\title{
Revealing Hidden Sounds through the Global Sound Movement
}

\author{
Philip Michael Holmes, Paresh Parmar \\ Global Sound Movement \\ University of Central Lancashire \\ \{pmholmes, pparmar\}@uclan.ac.uk
}

\author{
Mark Lochrie, Paul Egglestone \\ Media Innovation Studio \\ University of Central Lancashire \\ \{mlochrie, pegglestone\}@uclan.ac.uk
}

\begin{abstract}
This research presents a Global Sound Movement (GSM), that brings together cultures and communities to share their art form to a broader audience. The GSM enables those in social and/or economic need to express their music to a global audience. GSM focuses on the building, motivations and sustainability of communities by crafting ways to capture the sounds from within the environment. After months of on location recordings we introduce a unique set of values around the processes and methods we use to resurrected these hidden sounds. We use Human Computer Interaction $(\mathrm{HCl})$ methods as a way of collecting the samples and distributing via an online portal. Moving forward we are keen to explore the use of a toolkit to enable other researchers, practitioners and communities to assist in the collection process, building up larger sets of sounds on the GSM platform.
\end{abstract}

Sampling. Communities. Locative. Audio. Toolkit. Sounds. Ambience. Movement.

\section{INTRODUCTION AND BACKGROUND}

Global Sound Movement (GSM) is practice-led research within the arts. This works in progress paper introduces the project and reflects upon the practices, methodologies, ethics and nature of this kind of research. At a time when music platforms are exploding from the likes of Spotify to Tidal, whose goal it is to get unknown artists work mainstream a lot of controversy surrounds this sector with high profile artists suing (Ellis-Petersen, 2014) the ecosystems for not distributing the royalties fairly and in some cases removing themselves off the platform. This is problematic for the industry and with streaming services dominating this sector (Billboard) it isn't likely to go away.

Much research has been conducted in this area of sharing royalties within other forms of media, where you can pay what you think it's worth with platforms such as Humble Bundle (Humble Bundle, 2016). But also by academic researchers, exploring the use of recording a children's choir (sang in pieces), through basic technology, later to be compiled into an album which was made available on 'Band Camp' with a similar model. In this instance all artists and performers signed their 'Royalties' over to a charity based in Deli (Dubber, 2011). This approach has since been adopted by Gary Barlow and Andrew Lloyd Webber, by travelling around the Commonwealth recording communities perform the song 'Sing' (Jubileesing, 2012).
The key focus for GSM is to travel to International areas in social and / or economic need where music forms a part of the community's individual culture to help sustain communities (Harris, 2015; Kuznetsov 2010). Where hand built instruments are constructed from locally sourced materials and form the basis of the unique sound of the specific village, town or city (Trehub, 2015).

The GSM research team reside at seemingly opposite ends of the economic and social spectrum to many of the people in communities whose musical instruments become the raw material, subjects and objects of the work. The notion of a community of musicians enabling and assisting in the recording of their instruments by the academic research team raises several questions. Issues of power between researcher and participant and the ownership of Intellectual property; ownership of the recordings and ownership of the processes through which these are made are not unproblematic. Neither is the issue of beneficence should the project makes money. At the core of the response to these questions lies the formal, legal entity that is the Global Sound Movement. People have different motivations for engaging with collaborative academic projects. One common theme emerging from this and other work is that there must be some mutual benefit- and that benefit must be real, not perceived. (Egglestone, 2015; Dray, 2012). Laying the foundations of any mutually beneficial relationship between participants and researchers 
starts with ensuring that project goals are negotiated. All parties must be able to express their interests and discuss the benefits of more collaborative models of production or other acknowledgements of the shared nature of the undertaking, such as recompense in kind. The GSM team also attempted to address the imbalance of power caused by the remuneration of professional researchers and the 'free' contribution of the participants. The team acknowledged that participants' time is not free and experimented with a form of compensation offered to individuals for their loss of earnings. This is not payment for participation, transfer of ownership rights or any form of 'royalty' fees in the traditional sense, but recognition of participants as people who may be sacrificing payment from their usual means of livelihood in order to take part in a research project.

\section{GLOBAL SOUND MOVEMENT}

It is the connection between communities, music, technology and people that makes the project a 'movement'. This movement is about working with local musicians and instrument makers to record each individual note or sound these instruments made through a process called sampling. The sampling sessions take place in the performance areas or environments where these instruments are usually experienced. By recording these instruments in these specific environments, the ambience of the location becomes inherent to the sound and adds to the timbre of each instrument. The auditory presence of the ambient sound ensures the sonic characteristics of each instrument is completely unique and unreplaceable anywhere else. Second to the primary concern of GSM is the audio recording of geographical locations. By making ambient recordings, GSM manage to map the sonic territories that are visited. The recordings take place throughout the day and night providing the listener with a high resolution account of the sonic tapestry of the venue / GPS location. All recordings are completed at high resolution inline with broadcast standard.

All recordings are edited and sample libraries generated are available for sale to the international music community, predominately; composers, music producers, post production houses and DJs from the GSM website. All monies received from the sale of any product are sent to the group of musicians / communities that constructed the instruments or performed the loops. This would provide a unique income stream for the performers / musicians, and provides much needed finance to the communities. A unique set of values are placed on this to reveal a open sharing, learning, and creativity over profit and social capital (Kuznetsov, 2010).
The instruments recorded are unique, hand built and captured in uncontrolled environments. This is very different to the sample libraries available that are compiled under strict sonic control in recording studio environments designed to be acoustically dead. The GSM library instruments retain the environmental convulsion within each recording of each sample. In order to comply with the notion of ambient sonic cohesion, music producers may wish to emulate the reverberant space across other synthetic instruments, breaking away from the established reverb techniques and practices apparent within Western Music production. Musical scales, pitch and timbre can also be explored through the utilisation of the GSM sounds within modern western composition in order to further explore sonic texture. Over the last six months, the GSM has worked with a range of communities, that encompassed unique ambient auditory environments recording high resolution in attempt to map the sonic territories of the country.

\section{CONCLUSION}

The methods and processes used within the GSM have proven to be on interest amongst $\mathrm{HCl}$ researchers, from exploring the use of interaction within communities (Holland, 2013) to the ethics that surround participation and equality for this type of research-led practice. Collaborations between multiple international educational institutions are currently being pursued along with documentary film makers from New Mexico, USA. Future projects will be taking place Cyprus where GSM will be working with both Turkish and Greek Musicians and instrument makers to create a Cypriot sample library that has equal amounts of instruments from both sides of the island in attempt to unite the musical identity of the one geographical location (Harris, 2015).

It is indented to develop the recording sessions capturing the clean and ambient effected sounds. Along with experiments and recording of the ambient convulsions through impulse responses would develop possibilities for music producers, composers and post production houses. It is these processes and methods we use that enables us to capture this unique sounds, allowing the communities of musicians and instrument makers the ability to have their art experienced anywhere. We are also keen to explore the use of mobile, as a GSM toolkit for recording but also to allow users the ability to experience these unheard sounds with a free-to-play application. We propose to further this research with other musician academics and interaction design for children. As previously stated, the economic models are key to sustaining this project. We anticipate a change in how we approach this in the next few months. By changing the way royalties are paid, inspired by services 
likes Humble Bundle, where you can pay what you want and decide where your monies go. We would then be able to distribute monies across our entire network, ensuring a minimum percent is paid out to all artists.

\section{REFERENCES}

Bilboard, http://www.billboard.com/ (visited on 06 June 2016)

Christman, E., 2015. U.S. Recording Industry 2015: Streams Double, Adele Dominates. http://www.billboard.com/articles/business/68352 16/us-recording-industry-2015-streams-doubleadele-dominates-nielsen-music (03 March 2016)

Dray, S.M., Light, A., Evers, V., Dearden, A.M., Densmore, M., Kam, M., Marsden, G., Ramachandran, D., Sambasivan, N, Smyth, T., van Greunen, D. and Winters, N. Human Computer Interaction for Development: Changing $\mathrm{HCl}$ to Change the World. The Human-Computer Interaction Handbook: Fundamentals, Evolving Technologies and Emerging Applications. Jacko, JA, and Sears, A. (Eds.): Mahwah, NJ: Lawrence Erlbaum Associates, 3rd Edn.

Egglestone, P., Locke, M., Rogers, J., Spooner, J., Watts, R. 2015. Unlimited Theatre: Digital Playscripts. AHRC/NESTA Digital R\&D report (2015)

Ellis-Petersen, H., the Guardian. 2014. Taylor Swift takes a stand over Spotify music royalties. http://www.theguardian.com/music/2014/nov/04/t aylor-swift-spotify-streaming-album-sales-snub (03 March 2016).
Jubileesing. 2012. Sing, Gary Barlow \& The Commonwealth Band. http://www.jubileesing. $\mathrm{com} /$ (03 March 2016)

Dubber, A. 2011. Monkey on the Roof: Researching creative practice, music consumption, social change and the online environment. Creative Industries Journal, Vol. 4, Iss. 1, 2011

Trehub, S., E., Becker, J., Morley, I., P., Trans. R. Soc. B 2015370 20140096; DOI: 10.1098/rstb.2014.0096. Published 2 February 2015

Harris, R., Pease, R., 2015. 'Pieces of the Musical World; Sounds and Cultures'. Routledge.

Kuznetsov, S., and Paulos, E. 2010. Rise of the expert amateur: DIY projects, communities, and cultures. In Proceedings of the 6th Nordic Conference on Human-Computer Interaction: Extending Boundaries (NordiCHI 10). ACM, New York, NY, USA, 295-304. DOI=http://dx.doi.org/10.1145/1868914.1868950

Holland, S, et al. "Music interaction: understanding music and human-computer interaction." Music and Human-Computer Interaction. Springer London, 2013. 1-28.

Humble Bundle, https://www.humblebundle.com narrative-games-bundle (visited on 06 June 2016). 